\title{
VULNERABILIDADE E SAÚDE
}

\author{
Tânia Christiane Ferreira Bispo*, Augusto Cesar Costa Cardoso**
}

\begin{abstract}
Autora para correspondência: Tânia Christiane Ferreira Bispo - taniabispo@bahiana.edu.br
*Pós-doutora em Saúde Coletiva pela UFBA. Editora da Revista Enfermagem Contemporânea, Professora Adjunta da Escola Bahiana de Medicina e Saúde Pública.

**Pós-doutor em Saúde Coletiva Pela UFBA. Editor da Revista Enfermagem Contemporânea, Professor Adjunto da Escola Bahiana de Medicina e Saúde Pública.
\end{abstract}

A proposta da presente edição da Revista Enfermagem Contemporânea continua sendo valorizar a diversidade e atualidade na saúde, apresentando uma temática extremamente relevante acerca da vulnerabilidade e saúde. A ênfase está na reflexão sobre as pessoas em situações de vulnerabilidade em relação aos agravos aos quais estão expostas.

As considerações sobre a temática vulnerabilidade estão amplamente difundidas na literatura, sendo utilizadas nas mais diversas áreas do conhecimento. Para melhor compreensão a raiz etimológica do verbo vulnerável, derivada do latim palavra vulnerare, quer dizer provocar um dano, uma injúria. Nas pesquisas na área de saúde o termo popularizou-se e recebeu a conotação de um adjetivo, que qualifica aquele que é ou está mais susceptível a sofrer algum agravo à saúde'.

O grande entrave social, que são as crescentes situações de vulnerabilidade que acometem as pessoas, não surge instantaneamente, é uma problemática histórica e está relacionada com diversas motivações, conhecer os principais condicionantes, que induzem as pessoas às situações de vulnerabilidade, nos auxilia delinear um perfil sociodemográfico predominante desta população, e serve como parâmetro para o desenvolvimento de políticas, programas e projetos que minimizem as dificuldades a que esta população é exposta ${ }^{2}$.

Vale ressaltar que a acessibilidade das pessoas em situação de vulnerabilidade aos meios assistenciais de saúde é inibida, e basicamente restrita a questões de urgência e emergência ${ }^{3}$.

É importante também conhecer as principais morbidades que afligem as pessoas em situação de vulnerabilidade, pois apesar da sua heterogeneidade os determinantes sociais a que esta população está submetida são bem característicos.

A dignidade da população em situação de vulnerabilidade é desrespeitada em várias nuances da sua vida em comunidade. A ausência e $\circ$ desrespeito aos direitos humanos são pontos importantes para serem modificados e estimularem o avanço de medidas que favorecem a implementação das políticas públicas voltadas para este público ${ }^{4}$.

A publicidade dos agravos que aflige a pessoa em situação de vulnerabilidade é uma alternativa promissora de dar visibilidade a quem esta a margem da sociedade. É importante articular a publicidade às necessidades dessa população de modo a estimular a dissolução dos estigmas referentes à situação, em contrapartida as tentativas de desburocratização do acesso à saúde e de efetivo cumprimento dos princípios norteadores do Sistema Único de Saúde (SUS) ${ }^{5}$. 
A população em situação de vulnerabilidade estar exposta a vários fatores produzidos pelo modelo socioeconômico brasileiro, entre eles a desigualdade social acentuada e a violência. A falta de garantia de serviços e atenção a essa população representa estigmas não superados e produz problemas sociais e exprime em sua condição a exclusão de várias perspectivas: expulsão, desenraizamento e privação 5 .

A exclusão no sentindo de expulsão significa que não são aceitos em qualquer espaço de convivência, a exclusão como desenraizamento, pois é caracterizada como população que apresenta fragilização dos laços familiares ou interpessoais, e exclusão como privação, pois sua condição limita lugares em que pode ocupar, serviços que podem solicitar ou direitos universais como $\circ$ direito à moradia ou segurança ${ }^{6}$.

A vida expõe essa população à riscos específicos que merecem diferenciada atenção. Essas vulnerabilidades são a falta de segurança pública, relacionada a violência, com possibilidades de agressões físicas ou morais, o que leva a um estado de alerta e privação do sono. Estão expostos a ingestão de água de má qualidade, ou alimentação inadequada. A limitação do acesso ao atendimento em serviços de saúde, pois ainda não há uma cobertura satisfatória para atender a essa população. Além disso há a vergonha da sua condição de higiene e vestimentas ao buscar os serviços de saúde ${ }^{6}$.

papel do profissional de saúde então seria compreender a condição de vida de uma pessoa em situação de vulnerabilidade e auxiliá-lo à encontrar condições melhores de sobrevivência. Através de orientação à casas de apoio, ou à serviços específicos, ou mesmo estimulando o autocuidado. É compreender e estimular o conhecimento daquele cidadão. Além de garantir a atenção, proteção e vínculo da equipe de saúde com as pessoas em situação de vulnerabilidade.

O preconceito com a população em situação de vulnerabilidade é perceptível no cotidiano, e ignorar esta realidade torna-se uma barreira para a resolução ou amenização deste problema, ainda que o Estado deva se responsabilizar em cuidar de todos. O bem-estar do cidadão é garantido em legislação federal, porém, culturalmente, as pessoas que estão em situação de vulnerabilidade não são compreendidas como iguais a qualquer cidadão, pois se tornam alvo de significações preconceituosas $e$ estigmatizadas. As medidas legislativas e políticas públicas apresentam caráter resolutivo, ao mesmo tempo em que servem de estímulo para a compreensão de uma nova perspectiva sobre essa população, principalmente no setor saúde, em que promove a equidade no atendimento, enquanto combate a invisibilidade dessa população ${ }^{5}$.

\section{REFERÊNCIAS}

1. Nichiata LYI, Bertolozzi MR, Takahashi RF, Fracolli LA. A utilização do conceito "vulnerabilidade" pela enfermagem. Revista Latino-americana de Enfermagem. 2008; 16(5):923-928. doi: 10.1590/ S0104-11692008000500020

2. Brasil. Decreto $n^{\circ} 7.053$, de 23 de dezembro de 2009. Institui a Política Nacional para a População em Situação de Rua e seu Comitê Intersetorial de Acompanhamento e Monitoramento, e dá outras providências. Brasília, 2009.

3. Brasil. Lei $n^{\circ} 8.080$, de 19 de setembro de 1990. Dispõe sobre as condições para a promoção, proteção e recuperação da saúde, a organização e o funcionamento dos serviços correspondentes e dá outras providências. Diário Oficial da União 19 set 1990.

4. Brasil. Ministério da Saúde. Secretaria de Atenção à Saúde. Departamento de Atenção Básica. Manual sobre o cuidado à saúde junto a população em situação de rua. Brasília. DF. 2012.

5. Brasil. Ministério da Saúde. Secretaria de Gestão Estratégica e Participativa. Coordenação Geral de Apoio à Gestão Participativa e ao Controle Social. Saúde da população em situação de rua: um direito humano. Brasília. DF. 2014.

6. Brasil. Política nacional para inclusão social da população em situação de rua. Brasília. DF. 2008. 